\title{
HADIS-HADIS 'IMAMAH DALAM PERSPEKTIF AHMAD LUTFI FATHULLAH
}

\author{
RANGGA, FADHLINA AW. \\ Fakultas Ushuluddin, Filsafat Dan Politik UIN Alauddin \\ Makassar, Indonesia \\ Email: efawe70@gmail.com
}

\section{Abstrak}

Hadis-hadis 'imamah bertujuan menjelaskan hakekat serban serta pemahaman Ahmad Lutfi Fathullah tentang serban. Diharapkan dapat memberikan pemahaman yang komperehensif kepada masyarakat tentang serban. Penelitian bersifat library research. Hasil penelitian menjelaskan bahwa serban adalah pakaian yang digunakan di bagian kepala. atau menunjukkan kepada bentuk pakaian yang biasa digunakan seorang laki-laki di kepalanya, dengan model yang beragam, disesuaikan dengan budaya dan tradisi masing-masing daerah. Adapun pandangan Ahmad Lutfi Fathullah bahwa serban bukan bagian dari tradisi Islam dan bukan juga Sunnah melainkan budaya dan tradisi bagi bangsa Arab yang setiap muslim boleh mengikutinya atau mengabaikanya. Ahmad Lutfi Fathullah juga berpendapat bahwa memakai serban dengan niat mencontohi prilaku Rasulullah, maka akan menjadi Sunnah bagi orang yang melakukannya dan akan mendapatkan pahala disisi Allah SWT., karena segala sesuatu itu dinilai sesuai dengan niatnya.

\section{Keywords}

Hadis, 'imamah, Ahmad Lutfi Fathullah, serban 


\section{Pendahuluan}

Beragamnya model pakaian, khususnya di setiap agama memiliki ciri dan kesatuan tersendiri. Seperti pada pakaian tudung perempuan muslim maupun perempuan ortodoks, Yahudi dan Kristen. Pada kaum laki-laki juga terdapat pakaian khusus yang dikategorikan sebagai pakaian keagamaan, diantaranya adalah serban. Pemakaian serta pemaknaan serban telah diatur oleh setiap agama, salah satunya agama Yahudi, seperti yang dikutip pada artikel berjudul "The Priestly Turban had a hole in the top" karya J.E Marchant, "(Exo)You will place the turban on his head and put the holy insignia on the turban." Artinya: "Kau akan menempatkan serban di atas kepalanya dan meletakkan lambang suci pada serban itu". ${ }^{1}$

Serban adalah pakaian yang biasa dikenakan laki-laki untuk menutupi sebagian kepalanya dengan model yang beragam, disesuaikan dengan budaya masing-masing daerah. Serban adalah pakaian klasik bangsa Arab, yang dikenal dalam dunia Islam dan juga pra Islam. Serban atau 'imamah dalam bahasa Arab, adalah simbol kebangsawanan serta kemuliaan, juga pakaian terbaik yang dikenakan di kepala. Serban pada masa Nabi berbeda dengan masa sekarang. Pada wilayah Asia Tenggara kostum kehormatanya adalah songkok hitam, begitu pula dengan topi Turbus yang dikenakan oleh penduduk Turki. ${ }^{2}$ Indonesia memiliki kemajemukan paham religius yang dikembangkan dalam kelompok-kelompok agama. Adanya ragam kelompok Islam di Indonesia memaknai serban sebagai sebuah tradisi sekaligus Sunnah yang dicontohkan oleh

\footnotetext{
1J.E Marchant dalam artikelnya yang berjudul "The Prietsly Turban had a Hole in The Top", Juli 2009 http://yehspace.ning.com/profile/blogs/the-priestly-turban-had-a-hole $\underline{\text { h.1 }}$ paragraf 2 (diakses pada 3 juli 2019 pukul 09:00 WIB).

${ }^{2}$ Ali Mustafa Yaqub, Cara Benar Memahami Hadis (Cet. II; Jakarta: Pusataka Firdaus, 2016). h. 91.
}

TAHDIS Volume 10 Nomor 2 Tahun 2019 
Rasulullah SAW., sebagaimana dalam suatu riwayat yang artinya:

“....aku telah mendengar Ja'far ibn Amru ibn Huraits dari ayahnya berkata: aku melihat Rasulullah SAW. di mimbar memakai serban hitam yang kedua ujungnya telah beliau turunkan di antara kedua pundak. ${ }^{3}$

Hadis sahih di atas menyatakan bahwa ketika Rasulullah SAW. menyampaikan khutbahnya dengan keadaan mengenakan serban dan beliau menurunkan sampai di ujung pundaknya. Kemudian timbul pertanyaan, apakah orang yang tidak memakai serban dikatakan salah dan berdosa? Tampaknya tidak, karena tidak ada ulama satupun yang mengatakan hal itu salah atau berdosa karena hal tersebut tidak berkaitan dengan ibadah. Ini di kategorikan sebagai budaya dan adat bangsa Arab baik di kalangan muslim maupun non muslim di setiap daerah memiliki ciri khas masing-masing4.

Cara menggunakan serbanpun berbeda-beda, sebagaimana sabda Rasulullah SAW., yang artinya:

“...dari Abu Ja'far ibn Muhammad ibn Ali ibn Rukanah telah menceritakan kepada kami dari ayahnya berkata, .... Rukanah berkata, "Aku mendengar Nabi SAW. bersabda: "Perbedaan kita dengan musyrikin adalah diletakkannya 'imamah di atas peci.

\footnotetext{
${ }^{3}$ Muslim ibn al-Hajaj Abu al-Hasan al-Qsyairi al-Naisabur, al-Musnad al-Sahiih al-Mukhtasar Binaqli al-Adli an al-'adli ila Rasulillahi saw, Juz 2 (Beirut:Dar Ihya' al-Turas al-Arabi, T.Th.) 990.

${ }^{4}$ Ali Mustafa Yaqub, Cara Benar Memahami Hadis, cet. II (Jakarta:Pusataka Firdaus, 2016) 89-90.
} 
Ulama berbeda pendapat, tentang penjelasan Hadis tersebut di atas. Seperti pendapat ibn al-Qayyim, bahwa Nabi memakai peci tanpa serban dan terkadang pula Nabi memakai serban tanpa peci. ${ }^{5}$ Sedangkan al-'Azizi berpendapat, orang muslim mengenakan peci, lalu diletakkan serban setelahnya. Adapun menggunakan peci saja, maka identik dengan pakaian orang musyrik. Sementara al-Jazari mengutip dari sebagian Ulama, bahwa kami mengenakan serban di atas peci sedangkan mereka mencukupkan dengan serban. ${ }^{6}$ Al-Hafiz ibn al-Qayyim berkata, Nabi memakai serban sementara peci di bawahnya, Nabi terkadang menggunakan peci saja, atau serban saja. Dalam al-Jami' al-Shaghir dalam riwayat ibn 'Abbas, ia menjelaskan bahwa Rasulullah SAW., menggunakan peci putih. Pada riwayat lain, dari ibn 'Abbas bahwa Nabi memakai peci di bawah serban dan tanpa serban, memakai serban tanpa peci. Nabi juga mengenakan peci Yaman warna putih, serta peci yang mempunyai daun telinga pada waktu perang. Sesekali Nabi melepasnya lalu menjadikannya sutrah di antara tangannya takkala ia shalat. ${ }^{7}$

Di Indonesia, salah satu Ulama dan tokoh cendikiawan Islam, di era kontemporer adalah Ahmad Luthfi Fathullah. Beliau tokoh Ulama Hadis di Indonesia yang memiliki banyak karya, termasuk yang dibahas oleh mereka adalah tentang serban. Berdasarkan beberapa permasalahan di atas maka peneliti tertarik untuk lebih jauh mengkaji dan meneliti bagaimana hakikat serban? Bagaimana pemikiran Ahmad Luthfi Fathullah tentang serban?

\footnotetext{
${ }^{5}$ Muhammad bin Ali bin Muhammad bin Abdullah al-Syaukani, Nail al-Awțar tahqiq Isam al-Dīn al-Sibabiti, juz 2 (Kairo: Dar al-Hadìth, 1993) 127. ${ }^{6}$ Muhammad Asyraf al-Sadīqi, 'Aun al-Ma'bud Syarh Sunan Abī Dawud, Juz 2 (Beirut:Dâr al-Kutub al-'Alamiah, 1994) 87.

${ }^{7}$ Muhammad Asyraf al-Șadīqi, 'Aun al-Ma'bud Syarh Sunan Abī Dawud, 90.

TAHDIS Volume 10 Nomor 2 Tahun 2019
} 


\section{Pengertian 'Imamah}

'Imamah dalam bahasa Arab adalah selilit kain, jamak dari al-'ama'im yang berarti: pakaian lebar yang dililitkan di atas kepala agar terlindung dari panas dan dingin. Kata ammamahuta'miman adalah orang yang memakai serban. ${ }^{8}$ Menurut Khalil kata الْعَمَيُمَ bermakna suatu yang panjang dari tumbuhan. Dan dari

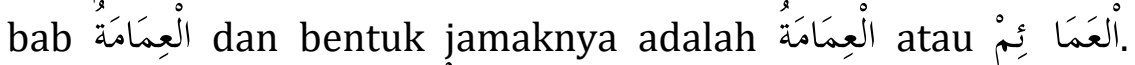

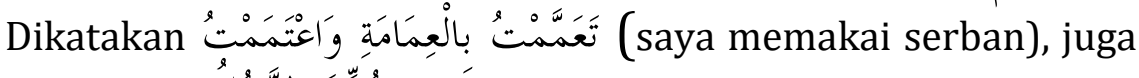

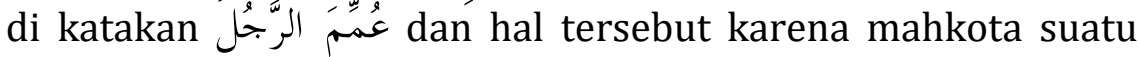
kaum adalah serban ${ }^{9}$.

Sementara dalam Kamus Besar Bahasa Indonesia (KBBI) berarti serban. Ini memiliki tiga variasi kata, yaitu: serban", "sorban" dan "surban". Bentuk bakunya adalah serban, sedangkan "sorban" dan "surban" tidak baku. Serban artinya ikat kepala yang lebar (biasa dikenakan orang Arab, haji dan sebagainya). ${ }^{10}$

Serban yang telah digunakan dan berkembang di tengah masyarakat Indonesia memiliki ragam bentuk yang berbedabeda. Teungku Zulkarnain menyebutkan bahwa terdapat empat puluh dua cara mengikatkan kain serban. ${ }^{11}$ Perbedaannya dipengaruhi oleh beberapa faktor, di antaranya topografi wilayah dan penyesuaian dengan dai-dai Islam yang memakai model serban itu; seperti 'imamah pada Tarekat Alawiyah, Habib Husein al-Hamid mengatakan bahwa terdapat lima model serban yang mayoritas dipakai habib-habib di Indonesia yaitu ${ }^{12}$ :

8Ahmad Warson Munawwir, Kamus al-Munawwir, (Surabaya:Pustaka Progresif, 1997) 133.

${ }^{9}$ Ahmad bin Faris bin zakariya' al- Qzawaini al-Razi, Mu'jam Maqayis al-Lugah, Juz 4 (T.Tt.::Dar al-Fikr: 1979) 17.

10Poerwadarminta, Kamus Besar Bahasa Indonesia. cet. III (Jakarta: Balai Pustaka, 1999) 145

${ }^{11}$ Hafshoh arrobbaniyah, Bentuk dan Makna Sorban di Indonesia, Skripsi, h. 5 ${ }^{12}$ Fahmi Hidayahtullael, "Pemahaman Hadis tentang Pemakaian Serban menurut Ahmad Lutfi Fathullah", Skripsi h. 33.

TAHDIS Volume 10 Nomor 2 Tahun 2019 
Di samping itu, bentuk serban pada Tarekat Qadiriyah dan Naqsabandiyah, sebagaimana penjelasan Muhammad Zuhri Bahrudin, sebagai narasumber. Dia memberikan sedikit pemaparan mengenai bentuk serban yang berlaku pada tarekat Qadiriyah dan Naqsabandiyah. "Serban itu bahkan para malaikat pun memakainya, sehingga tidak ada perbedaan antara mursyid dengan muridnya. Karena serban itu satu sunah, hanya berbeda pemakaiannya. Ada yang bentuknya mengenakan igal dan ada yang mengenakan rida atau hiasan di baju; Adapun bentuk serban pada jamaah Tabligh, memiliki paham yang serupa dengan tarekat Qadiriyah dan Naqsabandiyah bahwa yaitu disesuaikan dengan selera pemakai, tidak berdasarkan satu bentuk tertentu. Namun umumnya mereka memakai serban mengikuti bentuk serban dari India dan Pakistan.

Bentuk serban di wilayah Sumatera, khususnya Sumatera Utara, Riau dan sekitarnya sedikit berbentuk kerucut di ujung kepalanya dan kain serban dililitkan mengelilingi kerucutnya. Pemakaian serban seperti ini melibatkan peci dan kain serban. Peci dikenakan terlebih dahulu sebelum melilitkan kain serban di atas kepala. Peci yang dikenakan umumnya berbentuk lancip menyerupai kerucut, kemudian kain serban dililitkan mengelilingi permukaan bawah peci tersebut. Bentuk serban ini mirip dengan bentuk serban tentara India saat perang dunia I, namun jamaah al-Nazir umumnya mengenakan kain serban serta peci lancip berwarna hitam; dan yang terakhir, bentuk serban di Jawa, Blangkon.

Blangkon adalah penutup kepala yang dikenakan kaum pria sebagai bagian dari pakaian tradisional Jawa. Blangkon merupakan bentuk praktis dari iket, terbuat dari kain batik. Terdapat banyak versi legenda atau cerita rakyat mengenai asal usul blangkon, karena pada zaman tersebut masyarakat Indonesia, terutama Jawa dan Bali, menggunakan penutup 
kepala untuk mengusir roh-roh jahat yang mengganggu mereka. Blangkon yang berkembang di Jawa merupakan salah satu bentuk akulturasi budaya antara Jawa dan India, sedangkan bentuk akulturasi dari Arab itu lebih digunakan oleh masyarakat Jawa yang tinggal di pesisir pantai utara. Orang Islam yang masuk ke Jawa terdiri dari dua etnis yaitu keturunan Cina dari Daratan Tiongkok dan para pedagang Gujarat, India. Para pedagang Gujarat tersebut merupakan keturunan Arab yang sering memakai serban di atas kepala mereka. Serban yang menginspirasi masyarakat Jawa untuk menggunakan ikat kepala.

Fungsi serban pada umumnya, sebagai penutup kepala dan sekaligus pelindung dari terik matahari sebagaimana telah dijelaskan sebelumnya bahwa pada kondisi bangsa Arab serban berfungsi sebagai penutup kepala dan pelindung dari terik matahari dan debu. Di samping itu, serban berfungsi sebagai contoh perilaku seseorang. Utsman bin Affan RA. berkata, "Tidaklah seseorang melakukan suatu perbuatan kecuali Allah mengenakan padanya serbannya. Jika itu baik maka (serbannya) baik, dan jika buruk maka (serbannya) buruk." pengetahuan tentang hal ini telah sama-sama diketahui oleh mereka yang berakal dan lain-lainya, sampai orang yang baik lagi yang berbakti benar-benar tercium darinya aroma yang baik walaupun ia tidak memakai wangian (minyak wangi). Jadi tampak kebaikan aroma ruhnya, pada tubuhnya, dan pada pakaiannya. Sedangkan orang alim adalah sebaliknya. Orang yang sakit dan demam, tidak dapat mencium ini, tidak pula rasakan dan ketahui, bahkan demamnya membawanya kepada pengingkarannya. ${ }^{13}$

${ }^{13}$ Manshur bin Muhammad bin Abdullah al- Muqrin, Ensiklopedia ibn Qayyim al-Jauziyyah, Juz I, ([t.t]); Pustaka Azzam, 1423), h 55

TAHDIS Volume 10 Nomor 2 Tahun 2019 
Sementara fungsi serban pada tarekat Alawiyah, bahwa pemakaian serban oleh habaib merupakan bentuk penghormatan masyarakat atau pengikut tarekat ini terhadap jasa serta peran habaib sebagai pendakwah sekaligus sosok istimewa yang diyakini oleh mereka memiliki garis keturunan dengan Rasulullah SAW.14; fungsi serban pada majlis alFachriyah, untuk menghiasi diri pemakainya; Pada Tarikat Qadiriyah dan Naqsabandiyah, sebagai salah satu bentuk pembuktian umat Muslim terhadap sunah Rasulullah SAW.. Pemakaian serban dimaknai sebagai seruan untuk menebarkan kebaikan kepada sesama manusia. Mereka menjadikan ayat alQuran sebagai landasan dalil mengenai pemakaian serban dalam kelompok mereka, yaitu pada Q.S. Ali Imran 3:104; Pada jamaah Tabligh, menjadikan Rasulullah dan para sahabat sebagai referensi mereka dalam kehidupan sehari-hari, termasuk berpakaian. Pemakaian serban diyakini sebagai sebuah perwujudan dalam menjalankan Sunnah Rasulullah; Dan fungsi serban pada jamaah al-Nazir, sebagai bukti Ulama yang mengamalkan amalan-amalan Nabi Muhammad SAW. Serta menjadi saksi pada amalan- amalan tersebut; Sementara fungsi serban menurut majelis Ulama Indonesia, sebagai simbol syi'ar Islam sekaligus sebagai salah satu perangkat pakaian dari para tokoh besar dalam dunia Islam di Indonesia. ${ }^{15}$

\section{Serban di masa Rasulullah SAW.}

Adapun ukuran serban Rasulullah SAW., yaitu tidak terlalu besar yang dapat menyeliliti kepala pemakainya atau tidak terlalu kecil sehingga tetap dapat melindungi kepala dari

\footnotetext{
${ }^{14}$ Hafshoh arrobbaniyah, Bentuk dan Makna Sorban di Indonesia, Skripsi, h. 6

${ }^{15}$ Hafshoh arrobbaniyah, Bentuk dan Makna Sorban di Indonesia, Skripsi, h. 15.
}

TAHDIS Volume 10 Nomor 2 Tahun 2019 
panas dan dingin. Ukuran serban beliau berukuran sedang. Beliau melilitkannya di bawah rahang. Cara mengenakan yang seperti ini mengandung banyak manfaat, yaitu dapat melindungi leher dari panas dan dingin, sangat melindunginya terutama saat mengendarai kuda dan unta saat berhenti atau berjalan. 16

Rasulullah SAW. memiliki serban yang disebut sebagai alSahab. Serban itu pernah Rasulullah SAW. pasangkan kepada Ali. Rasulullah SAW. memakai sorban itu, dan pada bagian bawah serban Rasulullah SAW. memakai peci. Kadang beliau memakai peci tanpa dilengkapi dengan serban. Kadang juga memakai serban tanpa peci. Jika Rasulullah SAW. memakai serban, Rasulullah SAW. sedikit menurunkan sorbannya hingga ke bahu, sebagaimana Hadis Rasulullah SAW. yang artinya:

“...saya telah mendengar Ja'far ibn Amru ibn Huraits dari ayahnya berkata; "Aku melihat Rasulullah SAW. di mimbar dengan memakai 'imamah hitam yang kedua ujungnya telah ia turunkan di antara kedua pundaknya.(HR.Muslim). ${ }^{17}$

Dalam Hadis tidak ada keterangan yang menjelaskan berapa kadar serban yang semestinya harus dikenakan, sejatinya ukuran panjang dan lebarnya disesuaikan dengan ukuran pemakainya atau adat kebiasaan dan kondisi di masa itu baik ukuran maupun kualitasnya, iklim geografi juga memiliki pengaruh terhadap hal ini. Dianjurkan bagi yang mengenakan serban untuk mengulurkan ujung serban di antara dua pundak. Sebagai mana Hadis Rasulullah SAW:

${ }^{16}$ Abdul wahab abdul salam, fiqhu al-Albisati wa al-zinati. terj. Abu uwai, Andi syahril, Adab berpakaian dan berhias, cet. I (Jakarta: Pustaka Al-Kautsar 2014) 223.

${ }^{17}$ Muslim ibn al-Hajjaj Abu al-Hasan al-Qusyairi al-Nasaiburi, al-Musnad alsahih al-Mukhtasar binaqli al-'Adl an al-'Adl ila Rasulillahi sallallhu 'Alaihi wa Sallam, juz 2 (Beirut:Dar Ihya' al-Turas al-'Arabi, T.Th.) 990.

TAHDIS Volume 10 Nomor 2 Tahun 2019 
“...dari ibnu Umar berkata, "Apabila Nabi SAW. memakai 'imamah, ia mengurai imamah-nya antara dua pundaknya. "Nafi' berkata, "Ibnu Umar mengurai imamah-nya antara dua pundaknya. "Ubaidullah berkata, "Aku pernah melihat Al Qasim dan Salim pun melakukan seperti itu. (HR. Tirmidzi). ${ }^{18}$

Dalam kitab Zad al-Ma'ad ibn al-Qayyim menjelaskan bahwasanya kata "dzuabah" (ujung serban) tidak disebutkan dalam riwayat Jâbir tersebut di atas. Ini menunjukkan "dzuabah" tidak selalu dijulurkan di antara bahu oleh Nabi. Ketika kata dzuabah tidak disebutkan dalam Hadis di atas, maka dapat dijadikan dalil bahwa Rasulullah SAW. tidak selalu menjulurkan ujung serbannya. Menurut al-Mundziri, Hadis itu juga diriwayatkan oleh Muslim, al-Nasai, al-Tirmidzi dan ibn Majah.19

Ali al-Qari berkata saya telah mengkaji begitu teliti dalam kitab-kitab Hadis, sejarah dan sebagainya untuk mendapatkan gambaran berapa panjang serban Rasulullah SAW. Namun demikian penelitian ini ternyata tidak menghasilkan apa-apa sehingga saya menemui seorang yang sangat dipercaya dan amanah dan memberitahu kepadaku bahwa imam Nawawi telah menulis bahwa Rasulullah SAW. mempunyai dua serban, satu yang kecil dan satu yang besar. Panjang serban besar adalah tujuh hasta, sedangkan panjang serban yang kecil adalah dua hasta. ${ }^{20}$

\footnotetext{
${ }^{18} \mathrm{Abu}$ Isa Muhammad Isa bin Saurah al-Tirmidzi, al-Jami' al-Kabir, juz 3 (Beirut:Dar al-Gharb al-Islami, 1996) 349.

${ }^{19}$ Ibn al-Qayyim al-Jauziyyah, Zad al-Ma'ad fi Hadyi Khoir al-Ibad (Beirut:Maktabah al-Manar al-Islamiyyah, 1994), Juz 1, h. 130. Lihat pula Muhammad Asyraf al-Sadiqi, 'Aun al-Ma'bud Syarh Sunan Abu Dâwud, juz 11, 88.

${ }^{20}$ Maulana fazhul rahman azami dan Maulana muhammad zakariyya kandahlawi, Kumpulan hukum dan fadhilah, rambut, peci, sorban, gamis, dan siwak menurut Alquran dan hadis, cet. X (Bandung: Pustaka Ramadhan, 2008) 128.
}

TAHDIS Volume 10 Nomor 2 Tahun 2019 
Panjang atau lebar serban yang telah diriwayatkan oleh Aisyah RA. adalah tujuh hasta tidak berasas sama sekali. Demikian pula dengan Hadis yang diriwayatkan bahwa ketika Rasulullah SAW. dalam perjalanan memakai serban putih dan ketika di rumah memakai serban hitam yang terbuat dari kain kapas (dalam setengah riwayat disebutkan bertentangan). Ketika di perjalanan dan warna putih ketika di rumah dengan serban yang sama. Ini juga tidak berasas. Tidak ada bukti yang kokoh untuk menyokongnya. ${ }^{21}$ Munawi berkata bahwa Rasulullah SAW. kadangkala memakai kopiah tanpa serban adalah jelas menunjukan amalan yang biasa dilakukan Rasulullah SAW. ketika berada di rumah. Beliau tidak akan keluar rumah tanpa berserban. ${ }^{22}$

Berdasarkan penjelasan di atas, dapat dipahami bahwa peci dan serban, Rasulullah SAW. terkadang memakai peci bersama serban terkadang pula menanggalkan serbannya dan hanya memakai peci. Jadi keduanya sama-sama dibolehkan. Adapun warna serban Rasulullah saw. serban Rasulullah saw. ada tiga macam warna yaitu: warna hitam, putih, merah dan hijau. Sebagai mana yang di jelaskan oleh Sulaiman bin Abdullah dalam kitab Musannaf ibn Abi Syaibah yang artinya:

“...dari Sulaiman bin Abi Abdullah Ran amu dent. berkata bahwa pada saat ia berberjumpa muhajirin al-awwalun" (Para Sahabat dari kalangan Muhajirin yang paling awal berhijrah) mereka mengenakan serban tebal, berwarna hitam, putih, merah dan hijau".

21Maulana fazhul rahman aazami, Maulana muhammad zakariyya kandahlawi, Kumpulan hukum dan fadhilah, rambut, peci, sorban, gamis, dan siwak menurut Alquran dan hadis, h. 126.

22Maulana fazhul rahman aazami, Maulana muhammad zakariyya kandahlawi, Kumpulan hukum dan fadhilah, rambut, peci, sorban, gamis, dan siwak menurut Alquran dan hadis, h. 131. 
Rasulullah SAW. menggunakan serban warna hitam telah banyak dikemukan dalam riwayat yang shahih dan dapat dipercaya sebagai mana ketika Rasulullah memasuki fath Mekkah Rasulullah SAW. mengenakan serban hitam dan juga ketika Rasulullah SAW.. menyampaikan khutbahnya di atas mimbar Rasulullah SAW. mengenakan serban hitam, demikian pula warna putih diketahui melalui riwayat Mustadrak lil Hakim dan Tabrani. "Serban Qitri" (menunjukkan tempat serban dibuat) dengan warna kemerah-merahan. Hadis lain yang artinya:

“...dari Jabir bin Abdullah bahwa Nabi SAW. masuk pada hari Fathu Makkah dengan memakai serban hitam. (HR. Muslim). ${ }^{23}$

Di sisi lain, Rasulullah SAW. menyuruh menggunakan serban putih, sebagaimana sabda Rasulullah SAW. yang artinya:

“...dari Abu al-Darda berkata, "Rasulullah SAW. bersabda: "Sebaik-baik pakaian yang kalian pakai untuk mengunjungi Allah di kuburan dan masjid kalian adalah pakaian putih. ${ }^{24}$

Munawi menulis dalam Syarah Zailai bahwa memakai serban hitam adalah masnun (sunnah) sebagaimana yang dijelaskan dalam beberapa riwayat dan hadis pada penjelasan sebelumnya. Namun demikian pula dengan paling utama adalah berserban putih. Kelebihan berserban putih tidaklah

${ }^{23}$ Muslim bin al-Hajjaj Abu al-Hasan al-Qusyairi al-Nasaiburi, alMusnad al-sahih al-Mukhtasar binaqli al-'Adl an al-'Adl ila Rasulillahi sallallhu 'Alaihi wa sallam, juz 2 (Beirut;Dar Ihya' al-Turas al-'Arabi, T.Th.) 990.

24Ibnu Majah Abu 'Abdullah Muhammad bin Yazid al-Qazuwini, Sunan ibn Majah, juz 2 (Dar Ihya' al-Kitab al-'Arabiyah: Fayasl 'Aisi al-Babi alHalibi, T.Th.) 1181.

TAHDIS Volume 10 Nomor 2 Tahun 2019 
dilenyapkan dengan Rasulullah saw. memakai serban hitam atau para malaikat turun pada hari peperangan Badar dengan memakai serban berwarna kuning. ${ }^{25}$ Pemilihan warna selain warna putih mungkin karena didorong oleh faktor-faktor keringanan. Hendaklah dipahami bahwa dengan menyebut kelebihan pakaian putih di dalam hadis sampai pada kehidupan kubur akan tetap menjadi suatu peraturan umum yang meliputi semua benda-benda pakaian termasuk di dalamnya serban. Kedudukan warna putih tidak akan di atasi dengan peristiwaperistiwa yang jelas bertentangan. ${ }^{26}$ Jadi dengan demikian warna serban yang dikenakan oleh Rasulullah saw. beragam warnanya dan menurut para ulama bahwa yang paling utama diantara sekian warna serban yang dipakai Rasulullah adalah serban yang berwarna putih.

\section{Pandangan Ulama terhadap 'Imamah (serban)}

Ibnu al-Arabi menuturkan bahwa serban adalah Sunnah para Rasul dan tradisi para Nabi dan pemimpin. Menurut ibn alArabi, pernyataan Rasulullah SAW. "orang yang sedang berihram dilarang mengenakan gamis atau serban "hal ini hanya ditujukan kepada orang yang berihram saja namun serban dianjurkan untuk menutup kepala dengan tujuan untuk menghambakan diri dihadapan Allah SWT. Di antara sunnahsunnah menggunakan serban adalah memakai sesuai kebutuhan saja tidak boleh sombong serta membanggakan diri. ${ }^{27}$

${ }^{25}$ Maulana fazhul rahman aazami, Maulana muhammad zakariyya kandahlawi, Kumpulan hukum dan fadhilah, rambut, peci, sorban, gamis, dan siwak menurut Alquran dan hadis, 137.

${ }^{26}$ Maulana fazhul rahman aazami, Maulana muhammad zakariyya kandahlawi, Kumpulan hukum dan fadhilah, rambut, peci, sorban, gamis, dan siwak menurut Alquran dan hadis, 137.

27'Abd al-Rauf al-Munawi, Fayd al-Qadir Syarah al-Jami'al-Saghir, juz 4 (Mesir:al-Maktabah al-Tijariyah al-Kubra, T.Th.) 429.

TAHDIS Volume 10 Nomor 2 Tahun 2019 
Menurut al-Nawawi dalam kitab Syarah al-Muhadzzab, melepaskan atau menjulurkan ujung serban karena sombong maka hukumnya adalah haram, namun jika menjulurkanya karena selain dari itu maka hukumnya makruh. ${ }^{28}$

\section{Riwayat Hidup Ahmad Lutfi Fathullah}

Beliau lahir di Kuningan, Jakarta Selatan. pada tanggal 25 Maret 1964. Putra Betawi asli. Ayah dan ibunya, bernama Fathullah dan Nafisah. Ahmad Lutfi Fathullah merupakan putra betawi asli. Ayahnya, keturunan dari guru Mughni, Ulama besar Betawi di era akhir 1800- awal 1900 M. Nama lengkapnya, Abd al-Mughni ibn Sanusi ibn Ayyub ibn Qais. Ibunya Nafisah, anak dari seorang ketua travel haji (yang dulunya masih hitungan jari). Usianya 14 tahun Nafisah sudah pergi ke Masjidil Haram. Pertemuan mereka terjadi di dalam pesawat, ketika keduanya akan berangkat ke Haramain, walau berbeda kloter. ${ }^{29}$ Istrinya Jenah Azhari, wanita keturunan asli Syiria-Indonesia. Menikah tahun 1993, ketika berusia 29 tahun. Dari pernikahannya, dikaruniai tiga anak lelaki, yakni Hanin Fathullah, Muhammad Hadi Fathullah dan Rahaf Fathullah.

Ahmad Lutfi Fathullah diberikan pendidikan agama sejak usia dini, sehingga tumbuh menjadi anak yang berbakti. Ayah ibunya juga telah menanamkan motivasi, agar ia kelak menjadi seorang Ulama. Adapun pendidikannya, beliau memulai dari Sekolah Dasar Negri 01, Kuningan Timur Jakarta, lalu lanjut pendidikan madrasah di kampungnya, kemudian sekolah di

${ }^{28}$ Muhammad 'Abd al-Rahma al-Mubarakfuri, Tuhfatal-Ahwazi Syarah Jami' al-Tirmidzi juz 5 (Beirut: Dar al-Hadis, 2001) 335.

${ }^{29}$ Hidayati nur fajrina, "Pemikiran dan aktivitas dakwah Dr. Ahmad lutfi fathullah", Skripsi (Jakarta: Fak. Ilmu Dakwah dan Ilmu Komunikasi UIN Syarif hidayatullah, 2013), h. 35

TAHDIS Volume 10 Nomor 2 Tahun 2019 
Ponpes Modern Gontor Ponorogo (1983) ${ }^{30}$ Jatim, Lalu Ahmad Lutfi Fathullah melanjutkan kuliahnya S1 di Universitas Damaskus, Syiria (1989).Pada saat itu, tingkat kelulusan masih sangat rendah, sekitar 25-30 persen. Angkatan beliau yang masuk 1500 orang, yang lulus 100 orang, beliau berada pada peringkat 10. Beliau mengambil jurusan Hadis dan Tafsir Hadis, dan menyelesaikan pendidikannya selama empat tahun lebih. ${ }^{31}$ Setelah itu, melanjutkan S2 nya di University, Jordania tahun 1990, jurusan Ushul Fiqh. Dari sini, pengetahuan keagamaan Ahmad Lutfi Fathullah semakin mendalam. ${ }^{32}$ Gelar doktornya beliau raih dari Univesitas Kebangsaan Malaysia (UKM), jurusan Ilmu Hadis. Ia masuk di universitas ini pada tahun 1995, selesai tahun 1998, tapi baru diujikan pada tahun 1999.33

Di antara guru Ahmad lutfi Fathullah adalah Mustafa Diib al-Bugha, dan Wahbah Mustafa al-Zuhaili, cendekiawan Islam khusus dalam bidang perundangan Islam (Syariah). Ahmad Lutfi Fathullah sekarang bertempat tinggal kediaman dimana dia dilahirkan yaitu di kompleks Masjid Gatot Subroto kav. 26, Kuningan, JakSel. ${ }^{34}$ Dari keluarga mampu atau berkecukupan.

Ahmad Lutfi Fathullah merupakan seorang ulama yang produktif dalam berkarya. Karyanya tidak hanya buku, tapi juga karya digital. Mengenai karya, Ahmad Lutfi Fathullah, penulis mengambil data mengenai karya-karyanya dari berbagai jenis

\footnotetext{
${ }^{30}$ Ahmad Lutfi Fathullah, Hadis-hadis Lemah dan Palsu dalam Kitab Durratun Nasihin (Cet. IV; Jakarta Timur: Darus Sunnah Press, 2018), h. 117.

${ }^{31}$ Ahmad Lutfi Fathullah, Hadis-hadis Lemah dan Palsu dalam Kitab Durratun Nasihin, 117

${ }^{32}$ Ahmad Lutfi Fathullah, Hadis-hadis Lemah dan Palsu dalam Kitab Durratun Nasihin, 117

${ }^{33}$ Evie Hidayati, ddk, Penelitian ini berjudul: Metodologi Ahmad Lutfi Fathullah dalam Penyusunan Kitab Hadis Arba'n "Tela'ah Terhadap Buku 40 Hadis Mudah Dihafal Sanad dan Matan”, al-Tahdis I, no. I (2017), h. 40 ${ }^{34}$ Ali Darta, "Kontribuksi Dr. Ahmad Lutfi Fathullah dalam Perkembangan Kajian Hadis di Indonesia”, al-Razi 16.no. (2017). h. 145
}

TAHDIS Volume 10 Nomor 2 Tahun 2019 
dan betuk karya tulis ilmiah yang ada. Adapun karyanya yang paling terkenal adalah karya-karya dalam bentuk digitalisasi Hadis seperti :35 Rumus al-Tahdits fi 'Ulum al-Hadits li al-Ja'bari: Tahqiq wa Dirasah (tesis), kajian hadis kitab Dzurrat al-Nashin (disertasi), Hadis-hadis Keutamaan alquran, Rumus-rumus Hadis dan Rijal aI-Hadis, Hadis-hadis Lemah \& Palsu dalam Kitab Dzurrat al-Nashin, Menguak Kesesatan aliran Ahmadiyah, Fiqih Khitan Perempuan, Mencerdaskan Otak, Menjaga Hati Mahasiswa-mahasiswi melalui Wirid, Zikir, dan Doa, 40 Hadis Keutamaan Zikir dan Berdzikir, Membaca pesan-pesan Nabi dalam Pantun Betawi, Membuka Pintu Rezeki Melalui Wirid Pagi dan Petang, Jalan Santri Menjadi Ulama : Kiai dan Tips, dll.

Karya beliau dalam bentuk multimedia dan dibantu oleh para karyawan dan asistenya. Adapun karya dalam bentuk multimedia yaitu: ${ }^{36}$ alquran al-Hadi, DVD, Interaktif: indeks tematik Qur'an, DVD Metode belajar interaktif hadis dan ilmu hadis, DVD Interaktif: hadis-hadis keutamaan alquran, CD dan aplikasi android potret pribadi dan kehidupan Rasulullah SAW., dll.

\section{Pemahaman Ahmad Lutfi Fathullah tentang Hadis Serban}

Sebelum masuk kepemikiran Ahmad Lutfi Fathullah tentang serban, terlebih dahulu menyampaikan bahwa bagaimana cara Ahmad Lutfi Fathullah dalam memahami suatu Hadis tentang serban. Ahmad Lutfi Fathullah membagi enam metode yang harus dilakukan dalam memahami Hadis yaitu: ${ }^{37}$

${ }^{36}$ Hidayati nur fajrina, "Pemikiran dan aktivitas dakwah Dr. Ahmad lutfi fathullah", Skripsi. h. 45

${ }^{37}$ Fahmi Hidayahtullael, "Pemahaman Hadis tentang Pemakaian Serban menurut Ahmad Lutfi Fathullah", Skrisi, h.104

TAHDIS Volume 10 Nomor 2 Tahun 2019 
Pertama, meneliti kualitas Hadis, apakah Hadisnya sahih atau tidak sahih. Jika sahih, maka dilanjutkan; dan jika tidak, maka tidak perlu dipahami; kedua, a te memahami teksnya secara tekstual. Apakah setara tekstual Hadis tersebut bisa diterima atau tidak. Ketika suatu Hadis tidak bisa dipahami secara tekstual, maka Hadis tersebut mesti dipahami dengan tekstual terlebih dahulu, yakni apakah secara tekstual, Hadis tersebut dapat diterima atau tidak. Bila tidak, maka Hadis tersbut harus difahami secara kontekstual; Ketiga, ketika memahami Hadis secara kontekstual, harus melihat sebab munculnya Hadis tersebut (asbab al-wurud); keempat, melihat asbab al-wurud Hadis dapat diketahui latar belakang yang menyebabkan suatu Hadis muncul, dan mengetahui mana Hadis yang nasikh dan mana yang mansukh; kelima, melihat Fiqh al-Hadis nya seperti apa. Kemudian teks Hadis dapat diterjemahkan dan dapat dipahami secara tekstual dan bisa dengan kontekstual; keenam, melihat Hadis-Hadis pada tema yang sama. Ketika memahami Hadis, tidat cukup memahaminya dengan satu Hadis saja, tetapi harus pula melihat Hadis lainnya dengan tema yang sama. Hal itu karena suatu Hadis erat kaitannya dengan Hadis yang lain. Setiap Hadis tidak berdiri sendiri, namun memiliki kaitan dengan Hadis-hadis yang lainya. Banyak orang salah dalam memahami Hadis, karena memahaminya langsung secara tekstual. Kesalahan tersebut menjadi fatal takkala, memahami satu teks Hadis saja tanpa memperhatikan Hadis-Hadis lain yang memiliki tema yang sama.

Interpretasi Ahmad Lutfi Fathullah, pada Hadis pemakaian 'imamah, bahwa Rasulullah memakai 'imamah, akan tetapi tidak memberi perintah umatnya agar memakai serban. Rasulullah memakai sesuatu belum tentu ia memerintahkan umatnya agar memakai apa yang beliau kenakan. Dalam konteks ke-Arab-an dan ke-Madinah-an, mengenakan 'imamah adalah 
hal yang penting serta memiliki beberapa kegunaan, misalnya sebagai penutup kepala, juga penutup wajah ketika terjadi badai pasir maupun debu di mana saat itu agak sulit berlindung, jika harus berlindung di balik pohon atau batu besar. Cara yang paling mudah dengan berlindung di balik serban. ${ }^{38}$

Masyarakat Arab pra Islam, lahir sudah memakai 'imamah dalam kehidupan sehari-hari. Kondisi sosial-geografis menuntut hal itu. Rasulullah SAW. memakai 'imamah karena kondisi budaya Arab serta faktor geografis, sebab Nabi adalah seorang Arab. Contoh pada masa kini, orang yang memakai helm, tujuannya untuk keselamatan bukan simbol dari kesalehan. Juga seperti orang memakai masker wajah, agar terlindung dari polusi udara. Jadi, memakai serban, baik untuk kondisi tertentu.

Pemahaman Ahmad Lutfi Fathullah tentang 'imamah, hanyalah sebatas budaya, bukan Sunnah, ataupun bagian dari agama, namun sebagai tradisi atau budaya orang Arab, yang setiap kita boleh mengikuti atau mengabaikannya. Jika kemudian diniatkan mengikuti prilaku Rasulullah, maka akan mendapatkan pahala, tetapi jika tidak, maka tidak akan mendapat pahala. Jadi, memakai serban bukan sunnah bi dzatih seperti shalat qabliyah yang Rasulullah SAW. Perintahkan. ${ }^{39}$

Takkala seseorang ingin mencontoh Rasulullah SAW. disebabkan ia memakai 'imamah, maka boleh-boleh saja. Tetapi harus menghormati orang yang tidak memakai 'imamah. Di lain sisi, takkala ingin mengatakan harus mengenakan serban karena Rasulullah SAW,. , maka perlu dipahami terlebih dahulu, bahwa benar Rasulullah SAW., memakai serban, akan tetapi ia

\footnotetext{
${ }^{38}$ Fahmi Hidayahtullael, "Pemahaman Hadis tentang Pemakaian Serban menurut Ahmad Lutfi Fathullah", Skripsi, h. 106

${ }^{39}$ Fahmi Hidayahtullael, "Pemahaman Hadis tentang Pemakaian Serban menurut Ahmad Lutfi Fathullah", Skrisi, h. 107
}

TAHDIS Volume 10 Nomor 2 Tahun 2019 
tidak pernah memerintahkan apalagi mewajibkan ummatnya agar mengenakan serban. Disinilah fleksibelnya, karena bisa menilainya dari dua sisi, maka dapat dispahami disibukan disimpulkan mengenakan serban itu baik, namun apabila esok tidak memakainya, maka jangan dikritik apalagi dihujat. Kesalehan seseorang, bukan diukur dari 'imamah dipakainya. ${ }^{40}$

Rasulullah mengenakan serban karena tiga hal, sebagai manusia biasa; sebagai Nabi dan Rasul; sebagai seorang pemimpin. Dari tiga keriteria ini, ketika Rasulullah memakai serban, bukan karena beliau seorang Nabi, bukan juga beliau seorang pemimpin, akan tetapi sebagai manusia biasa. Pendapat tersebut sama dengan pendapat Syuhudi Ismail, al-Qarali, ibn Asyur dan al-Dahlawi yang menyatakan bahwa dalam memahami Hadis perlu kiranya menghubungkan dengan posisi Rasulullah SAW., ketika mengeluarkan Hadis tersebut. ${ }^{41}$

Ahmad Lutfi Fathullah berpendapat, Hadis tentang cara Rasulullah SAW. memakai 'imamah sama saja dengan orang Arab yaitu, baik diselempangkan atau dililit-lilit seperti kopiah di kepala. Hal itu merupakan budaya Arab; sebab dalam memakai 'imamah dan sarung, Rasulullah SAW., tidak pernah menjelaskan secara detail, karena hal tersebut bukanlah bagian dari agama, namun bagian dari kebutuhan manusia sendiri. Rasulullah SAW. hanya mengajarkan apabila ingin mengerjakan sesuatu haruslah mendahulukan sebelah kanan. Dan itu hanyalah aturan umum untuk semua jenis pakaian, bukan aturan khusus memakai 'imamah. Rasulullah SAW., dan orangorang Arab lainnya memiliki cara tersendiri dalam memakai

\footnotetext{
${ }^{40}$ Fahmi Hidayahtullael, "Pemahaman Hadis tentang Pemakaian Serban menurut Ahmad Lutfi Fathullah", Skrisi, h. 108

41M. Syuhudi Ismail, Hadis yang Tekstual Dan Kontekstual: Telaah Ma'an al-Hadis tentang Ajaran Islam yang Universal, Temporal dan Lokal (jakarta: Bulan Bintang, 2009) , h. 4
} 
'imamah. Pada musim panas mereka memakai serban sebagai pelindung dari debu dan panasnya terik matahari, apabila musim dingin, serban dipakai sebagai pakaian tambahan di samping mengenakan baju tebal untuk menghangatkan tubuh.

Hadis Rasulullah SAW., tentang memakai serban pada hari fath al-Makkah, Ahmad Lutfi Fathullah menuturkan itu pada saat peristiwa (fath al-Makkah) yaitu ketika kota Makkah dibebaskan dari kaum Musrikin pada bulan Ramadhan, ${ }^{42}$ Rasulullah SAW. memasuki kota Mekah dengan memakai 'imamah berwarna hitam, tidaklah menunjukkan pada suatu kewajiban. Warna tersebut bersifat kondisional. Olehnya, tidak ada kewajiban mengikutinya baik dari segi warna, ataupun cara memakainya.

Faktor yang bisa jadi melatar belakangi Rasulullah SAW. mengenakan pakaian hitam ketika peristiwa itu adalah kondisi dan situasi perang. Pada fath al-Makkah, beliau sebagai tentara, panglima perang pada saat Makkah dibebaskan dari orangorang musrik, jadi wajar bila mengenakan warna keberanian, yakni warna hitam. Karena dalam Hadis, warna pakaian yang pernah digunakan Rasulullah SAW. cukup beragam, yaitu merah, hijau, hitam, serta sering menggunakan wama putih. Rasulullah SAW. sangat suka memakai pakaian putih. Namun Rasulullah SAW. tidak mewajibkan umatnya untuk mengenakan pakaian dengan warna tertentu, tidak terkecuali warna putih walapun warna favoritnya.

Masyarakat Indonesia memiliki tradisi tertentu dalam memakai serban. Ada yang berpendapat bahwa tradisi memakai serban adalah hanya orang yang sudah menunaikan ibadah haji. Yang lainnya berpendapat, orang yang khutbah harus memakai 'imamah. Ini adalah sebuah tradisi dan budaya yang

${ }^{42}$ Al-Wahidi, Asbab al-Nuzul, ([t.c]; Baerut: 'Alam al-Kutub, [t.th.]), h. 295.

TAHDIS Volume 10 Nomor 2 Tahun 2019 
berkembang di tengah-tengah masyarakat yang tidak penting dipermasalahkan. Juga bahwa anggapan tersebut tidak boleh dijadikan sebagai hukum agama, misalnya seorang khotib tidak akan sah dalam menyampaikan khutbah jika tidak mengenakan serban" atau "sudah haji tapi tidak memakai serban". Ini adalah sebuah contoh pemahaman yang salah. Seorang ustaz atau kiai tidak diukur dari serban yang dipakai. Demikian juga keimanan dan kesalehan seorang muslim. Keimanan dan kesalehan dilihat dari ilmu, ketakwaan dan amal ibadah.

Pakaian orang Indonesia dengan orang Arab memiliki perbedaan yang jelas. Demikian juga Orang Yaman dan Orang Turki. Orang Cina dan orang Indonesiapun memiliki perbedaan. Biarlah mereka dengan budayanya masing-masing. Ssesama muslim harus saling menghormati, menyayangi, mengasihi,dan mengayomi. Perbedaan pakaian bukan penghalang untuk bermuamalat. Budaya boleh berbeda, namun prinsip syariat dalam berpakaian harus tetap dipegang erat.

Di lndonesia, mayoritas Ulama dan kiai mengenakan peci hitam. Peci berbeda dengan serban. Namun keduanya memiliki hukum yang sama, yakni sebagai penutup kepala. Peci dan serban bukan bagian dari agama. Di indonesia, ada sebuah penutup kepala khas Jawa yang biasa disebut dengan blangkon. Peci bisa disamakan dengan belangkon dengan syarat tidak ada makna mistik di dalamnya. Baik serban, peci, maupun belangkon memiliki model yang beragam. Serban, misalnya, serban di Indonesia berbeda dengan serban yang ada di Arab. Begitu pula dengan peci, berbeda antara peci Indonesia dengan peci Maroko. Dengan demikian, serban dan peci adalah budaya bukan bagian dari agama. Adapun Hadis yang mengatakan bahwa shalat dengan mengenakan peci atau serban akan mendapatkan pahala yang sangat besar dibandingkan dengan shalat tanpa mengenakannya adalah Hadis da'if yang tidak dapat diamalkan. 
Di sini dapat disimpulkan bahwa Ahmad Lutfi Fathullah dalam memandang serban adalah sebagai budaya dan tradisi bagi bangsa arab karena serban hanyalah pakaian biasa yang dapat memakai siapapun yang ingin memakainya, namun memakai serban yang diniatkan dengan tujuan mengikuti Rasulullah SAW., maka memakai serban itu adalah sunnah karena mengikuti Rasulullah dalam arti sebagai Nabi dan Rasul yang dalam setiap perilaku dan akhlaknya bernilai ibadah dan pahala di sisi Allah. Sebagaimana sabda Rasulullah yang artinya: "Dan barangsiapa yang menghidupkan sunnahku, maka ia telah mencintaiku. Dan barangsiapa yang telah mencintaiku, maka aku bersamanya di Surga." 43

\section{Kesimpulan}

Serban adalah pakaian yang yang di kenakan di kepala. Definisi yang lebih luas, serban menunju kepada pakaian yang biasanya dipakai oleh seorang lelaki yang bisa saja memenuhi seluruh kepalanya dengan model-model tertentu sesuai dengan tradisi dan budaya yang berlaku di suatu daerah tertentu. Ahmad Lutfi Fathullah memahami serban hanyalah sebagai budaya, bukan Sunnah, Rasulullah mengenakan serban ada tiga kriteria: Pertama, beliau adalah sebagai manusia biasa. Kedua, beliau sebagai seorang Nabi. Ketiga, beliau sebagai seorang pemimpin. Dari tiga keriteria tersebut, ketika Rasulullah mengenakan serban, bisa dilihat bahwa Rasulullah mengenakan serban bukan karena beliau seorang Nabi, dan manusia biasa, maka serban itu bermakna hanya pakaian saja. Jika beliau memakai serban karena kapasitasnya sebagai Nabi dan Rasulullah dan mengikuti karena ingin mencontoinya maka

${ }^{43}$ Muhammad bin 'Isa bin Saurah bin Musa bin al-D $\{$ ahak, Sunan alTurmuzi, al-Jami` al-Kabir Juz 4 ([t.c]; Baerut: Dar al-Garb al-Islamiyyah, 1998 M), h. 343.

TAHDIS Volume 10 Nomor 2 Tahun 2019 
akan mendapatkan pahala karena niatnya. Oleh karena itu, sama sekali tidak dipermasalahkan seorang muslim mengenakan serban atau tidak. Ali Mustafa Ya'qub memahami bahwa Rasulullah memakai serban, itu adalah benar, berdasarkan hadis sahih, yaitu ketika Rasulullah maemasuki fath Mekkah. Namun agar dipahami bahwa Rasulullah SAW. memakai serban itu dalam kapasitasnya sebagai orang Arab, karena orang orang musyrikin seperti Abu Jahal, Abu Lahab, dan sebagainya juga memakai serban. Dalam berpakaian, Islam hanya mengamanatkan kriteria saja, yaitu dengan rumus 4T: tutup aurat, tidak transparan, tidak ketat, dan tidak menyerupai pakaian lawan jenis. Tentang model dan bentuknya, Islam tidak membatasi apalagi melarang model pakaian apa saja. Apabila empat kriteria tadi terpenuhi maka umat Islam dipersilakan berpakaian yang ia sukai dan dianggap cocok untuk lingkungannya.

Ahmad Lutfi Fathullah berpendapat bahwa serban bukanlah ajaran Islam ataupun Sunnah melainkan tradisi dan budaya bagi bangsa Arab. Artinya boleh bagi setiap muslim mengikutinya atau mengabaikannya. Ahmad Lutfi Fathullah memandang bahwa memakai serban itu boleh-boleh saja hukumnya mubah namun jika memakai karena niatnya untuk mengikuti sunnah Rasulullah SAW. maka akan mendapatkan pahala begitupun dengan sebaliknya. 


\section{DAFTAR PUSTAKA}

Alquran al-Karim

Al-'Abasi, Abu Bakar bin Abi Syaibah, 'Abdullah bin Muhammad bin Ibrahim 'Usman Khawasiti. Musannaf fi al-Ahadis wa al-Asar, Juz 5, Cet. I; Maktabah al-Rusyd: Riyad\} 1409.

Al-Albani, Muhammad Nashiruddin. Silsilah al-Hadis al-Da'if wal

Maudhu'ah, terj. A. M. Basalamah, Silsilah Hadis Da'if dan Maudu', Cet. III; Jakarta: Gema Insani Press, 1999.

Poerwadarminta. Kamus Besar Bahasa Indonesia, Cet. III; Jakarta: Balai Pustaka, 1999.

Arrobbaniyah, Hafshoh. Bentuk dan Makna Sorban di Indonesia, Skripsi, Depok: Fak. Ilmu Pengetahuan Budaya UI, 2014. Azami, Maulana fazhul rahman dan Maulana muhammad zakariyya kandahlawi. Kumpulan Hukum dan Fadhilah, Rambut, Peci, Sorban, Gamis, dan Siwak Menurut alquran dan Hadis, Cet. X; Bandung: Pustaka Ramadhan, 2008.

Al-Azdi, Abu Dawud Sulaiman bin al-Asy 'as bin Ishaq bin Basyir bin Syadad bin 'Amr, Sunan Abi Dawud, Juz 4, Beirut: alMaktabah al-'Isriyyah Saidan, t.th.

Badruz, Ahmad Dimyanti Zaman, Zikir Berjama'ah Sunnah atau Bid'ah, pengantar Ali Mustafa Yaqub, Jakarta: Republika, 2003.

Darus Sunnah Internasioanl Insititute for Hadith Sciences Indonesia- Malaysia ke-12, Jakarta1435 H/ 2014 M, Al-Dahak, Muhammad bin 'Isa bin Saurah bin Musa bin. Sunan al-Turmuzi, al-Jami' al-Kabir. Juz 4. ([t.c]; Baerut: Dar alGarb al-Islamiyyah, $1998 \mathrm{M}$.

-Muh\}mmad bin 'Isa bin Saurah bin Musa bin. Sunan al-

Turmizi. Juz 4. Cet. II; Mesir: Syarikah maktabah wa Matba'ah Mustafa al-Babi al-Halibi, 1975 M. 
Darta, Ali. "Kontribuksi Dr. Ahmad Lutfi Fathullah dalam Perkembangan Kajian Hadis di Indonesia", Al-Razi 16.no. 2017.

Fajrina, Hidayati nur. Pemikiran dan Aktivitas Dakwah Dr. Ahmad Lutfi Fathullah, Skripsi, Jakarta: Fak. Ilmu Dakwah dan Ilmu Komunikasi UIN Syarif hidayatullah, 2013.

Al-Fathullah, Ahmad Lutfi. Hadis-hadis Lemah dan Palsu dalam

Kitab Durratun Nasihin. Cet. IV; Jakarta Timur: Darus Sunnah Press, 2018.

Al-Gazali, Muh\}ammad. al-Sunnah al-Nabawiyyah: Baina Ahl alFiqh wa Ahl al-Hadis, terj. Muh\}ammad al-Ba>qir, Studi Kritis atas Hadis Nabi saw. antara Pemahaman Tekstual dan Kontekstual. Cet. II; Bandung: Mizan, 1992.

Hartono, Perkembangan Pemikiran Hadis Kontemporer di Indonesia: Studi atas Pemikiran Abdul Hakim Abdat dan Ali Mustafa Yaqub, Tesis, Jakarta: Pascaserjana UIN Syarif Hidayatullah, 2009.

Hidayati, Evie ddk. Penelitian ini berjudul: Metodologi Ahmad Lutfi Fathullah dalam Penyusunan Kitab Hadis Arba'in “Tela'ah Terhadap Buku 40 Hadis Mudah Dihafal Sanad dan Matan", Al-Tahdis I, no. I (2017).

Hidayatullael, Fahmi. Pemahaman Hadis tentang Pemakaian

Serban Menurut DR. Lutfi Fathullah, Skripsi, Jakarta; Fak. Ushuluddin UIN Syarif Hidaya Thulla (2018).

Hidayatulloh, Agus dkk. Al-Jamil; alquran Tajwid Warna, Terjemah Per Kata, Terjemah Inggris, Bekasi: Cipta Bagus Segara, 2012.

Himpunan Fatwa Dewan Syariah Nasional Edisi Ketiga di terbitkan atas Kerjasama DSN MUI dengan Bank Indonesia (BI) , Gaung Persada, 2006. 
Idris, Abdul Fatah. Studi Analisis Tahrij Hadis-Hadis Prediktif dalam kitab Al-Bukhari, Semarang: Lembaga Penelitian IAIN Walisongo Semarang, 2012.

Al-Isam al-Dīn al-Siba>biti, Juz 2, Kairo: Dar al-Hadīth, 1993.

Ismail, Abustani Ilyas dan La ode, Pengantar Ilmu Hadis, Cet.II;

Surakarta: Zahadaaniva Publishing, 2013.

Ismail, M. Syuhudi. Hadis yang Tekstual Dan Kontekstual: Telaah Ma'an al-Hadis tentang Ajaran Islam yang Universal, Temporal dan Lokal, jakarta: Bulan Bintang, 2009.

Ismail, M. Syuhudi. Hadits Nabi Menurut Pembela Pengingkar dan Pemalsunya, t.d.

Ismail, M.Syuhudi. Pengantar Ilmu Hadis, Cet. X; Bandung: Angkasa Bandung, 1994.

J.E Marchant dalam artikelnya yang berjudul "The Prietsly Turban had a Hole in The Top", http://yehspace.ning.com/profile/blogs/the-priestly-

turban-had-a-hole h.1 paragraf 2, Juli 2009.

Al-Jauziyyah, Ibn al-Qayyim.Zad al-Ma'ad fi Hadyi Khoir al-'Ibad, Beirut: Maktabah al-Manar al-Islamiyyah, 1994.

Al-Jistani, Abu Dawud Sulaiman bin al-Asy'as bin Ishaq bin Basyir bin Syaddad bin 'Àmr al-Azdi al-Sayyi. Sunan Abi Dawud. Juz 4. ([t.c.]. Beirut: al-Maktabah al'Asriyah,[t.th.].

Kementerian pendidikan dan kebudayaan, KBBI Daring. https://kbbi.kemdikbud.go.id/entri/serban (Diakses pada 20 September 2019).

Kementerian Pendidikan Nasional, Kamus Bahasa Indonesia, Jakarta: Pusat Bahasa, 2008.

Al-Khattab, Abu Sulaiman. Ma'alim al-Sunan. Juz 2. [t.t]; Kairo: Dar al-Kutub al-'Ilimyah, $2005 \mathrm{M}$. 
Kitiarsa, Pattana. Menuju Sosiologi Komodifikasi Agama dalam Bryan S. Turner, Sosiologi Agama, Yogyakarta: Pustaka Pelajar, 2013.

Mahfudhon, Ulin Nuha. Meniti Dakwah di Jalan Sunnah; Biografi Kiai Ali Mustafa Yaqub, Jakarta, Yayasan Wakaf DarusSunnah, 2018.

Miski, Pemahaman Hadis Ali Mustafa Yaqub, Studi atas pengharaman dalam konteks Indonesia, Riwayah, 2. no. I 2016.

Al-Misri, Abu 'Abdillah Muhammad bin Salamah bin Ja'far bin 'Ali bin Hakmun al-Qada'i. Juz 1. Cet. I: Baerut: Mu'assasah alRisalah, 1986 M.

Mubarakfuri, Muhammad 'Abd al-Rahma. Tuhfatal-Ahwazi

Syarah Jami' al-Tirmidzi, juz 5, Bairut: Dar al-Hadis, 2001. Munawi, 'Abd al-Rauf. Fayd al-Qadir Syarah al-Jami' al-Saghir, Juz 4, Mesir: al-Maktabah al-Tijariyah al-Kubra, [t.th.].

Munawwir, Ahmad Warson. Kamus al-Munawwir, Surabaya: Pustaka Progresif, 1997.

Al-Muqrin, Manshur bin Muhammad bin Abdullah. Ensiklopedia Ibnul Qayyim al-Jauziyyah, Juz I, [t.t]; Pustaka Azzam, 1423.

Al-Naisaburi, Muslim bin al-Hajaj Abu al-Hasan al-Qsyairi, AlMusnad al-Sahiih al-Mukhtasar Binaqli al-Adli an al-'adli ila Rasulillahi saw, Juz 2, Beirut: Dar Ihya' al-Turas alArabi, t.th.

Al-NasaI, Abu 'Abd al-Rahman Ahmad bin 'Ali al- Hurasani. alSunan al-Sagir li al-Nasai. Juz 4. Cet. II; Halab: al-Maktab al-Mat\}bu>'at al-Islamiyah, 1406 H/1986 M.

Nurdin, Nasrullah. prof. Dr. KH. Ali Mustafa Yaqub, Muhaddis Nusantara Bertaraf Internasional, Lektur keagamaan 14, no. I (2016). 
Al-Qardawi, Yusuf. Membedah Islam Estrim. Penerjemah Alwi. A.M, Cet. IX; Bandung: Mizan, 2001.

Al-Qazuwaini, Ibn Majah Abu 'Abdullah Muhammad bin Yazid.

Sunan Ibnu Majah. Juz I. ([t.c.; t.tp: Dar Ihya' al-Kutub al'Arabiyah, t.th.]).

Sunan ibn Majah, Juz 2, ([t.c.; t.tp: Dar Ihya' al-Kutub al'Arabiyah, t.th.]).

al-Razi, Ahmad bin Faris bin zakariya' al- Qzawaini. Mu'jam Maqayis al-Lugah, Juz 4, [t.tp]: Dar al-Fikr, 1979.

Șadīqi, Muhammad Asyraf.'Aun al-Ma'bud Syarh Sunan Abī Dawud, Juz 2, Beirut: Dâr al-Kutub al-'Alamiah, 1994.

Salam, Abdul Wahab Abdul. Fiqhu al-Albisati wa al-Zinati. ter. Abu Uwai, Andi Syahril, Adab Berpakaian dan Berhias, Cet. I; Jakarta: Pustaka Al-Kautsar 2014.

Sattar, Abu Talhah bin Abdul. Libasu al-Rasul wa al-Sahabah wa al-Sahabiyat Ajma'in, terj. Abu Huzaifah,dkk. Tatabusana para Salaf, Cet. I; Solo: Zamzam, 2008.

al-Suyuti, Jalaluddin. Zuhar al-Ruba' 'Ala al-Mujtaba Syarah Sunan al-Nasa'. Juz 2. ([t.c]; Kairo: Bait al-Afkar alDawuliyah, $2005 \mathrm{M}$.

Syaukani, Muhammad bin Ali bin Muhammad bin Abdullah. Nail al-Awțar Tahqiq, t.d.

Tahwilah, Abdul wahab abdu al-salam. Adab Berpakain dan Berhias, Cet. I; Jakarta: Pustaka al-Kautsar, 2014.

Al-Tirmidzi>, Abu> Isa Muh\}ammad Isa bin Saurah. al-Ja>mi' alKabi>r, Juz 3, Beirut: Dar al-Gharb al-Isla>mi, 1996.

Al-Wahidi. Asbab al-Nuzul. [t.c]; Baeru>t: 'Alam al-Kutub, [t.th.]. Yaqub, Ali Mustafa. al-T\{ariq al-S\}ah\}i>h\}ah\} fi> Fahmi alSunnah\} al-Nabawiyyah\}, terj. Mahfudh hidayat lukman, Cara Benar Memahami Hadis, Cet.II; Jakarta: Pustaka Firdaus, 2016. 
,Ali Mustafa. Hadis hadis Bermasalah, Cet. I; Jakarta: Pustaka Firdaus. 2003.

--------,Ali Mustafa. Haji Pengabdi Setan, Cet. V; Jakarta, PT. Pustaka Firdaus, 2019.

-,Ali Mustafa. Kerukunan Umat dalam Perspektif alquran dan Hadis. Cet. I; Pejatan Barat: Pustaka Firdaus, 2000.

--------,Ali Mustafa. Sejarah dan Metode Dakwah Nabi, Jakarta: Pustaka Firdaus, 1997.

--------,Ali Mustafa. Setan Berkalung Serban, Cet. I; Jakarta: Pustaka Firdaus, 2014. 